\title{
O Serviço Social e a "responsabilidade social das empresas": o debate da categoria profissional na Revista Serviço Social \& Sociedade e nos CBAS
}

\section{Social Services and "corporate social responsibility": the discussion of the professional category in revista Serviço Social \& Sociedade and in the CBAS}

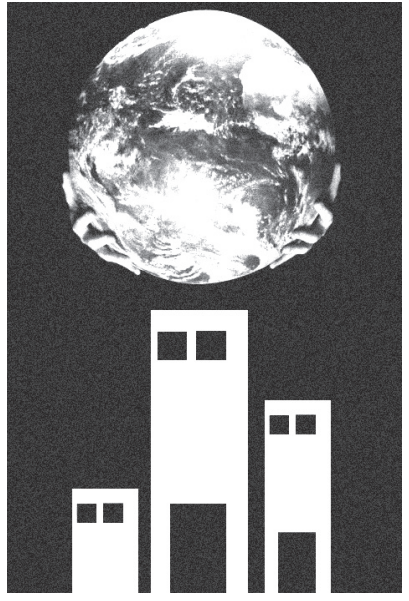

Franciane Cristina de Menezes*

Resumo: O objetivo deste texto é contribuir para o debate acerca da responsabilidade social das empresas dentro do Serviço Social. Por trás de projetos sociais, fundações sociais e patrocínios, tem um nítido interesse de classe - é uma estratégia de hegemonia. Nossa pesquisa foi motivada pelo fato de que a área de "responsabilidade social das empresas" mostra-se como um novo campo de atuação para os assistentes sociais e faz-se necessários conhecer quais são seus reais objetivos.

Palavras-chave: Política social. Serviço Social. Assistência social. Terceiro setor. Responsabilidade social das empresas.

\begin{abstract}
This text aims at contributing to the discussion about Corporate Social Responsibility (CSR) and its real intentions. Behind social projects, social foundations or sponsorship there's a clear social class objective - it is a strategy of hegemony. The motivation for this research was the fact that the CSR is a new place of work for social workers and we need to know how true these objectives are.

Keywords: Social policy. Social Services. Social assistance. Third sector. Corporate social responsibility.

* Doutoranda em Serviço Social pela Universidade Federal do Rio de Janeiro/UFRJ; mestra em Serviço Social pela Universidade do Estado do Rio de Janeiro (UERJ), Rio de Janeiro/RJ — Brasil; assistente social formada pela Universidade Federal de Juiz de Fora (UFJF). E-mail: fcmenezes@ @erra.com.br.
\end{abstract}




\section{Introdução}

situação das políticas sociais e a sua forma de condução histórica
no país (ineficiente, ineficaz e caracterizada por burocracia exces-
siva) se agravou de forma contundente, principalmente a partir dos
anos 1990 , no governo FHC, que empreendeu a contrarreforma do Estado (cf. Behring, 2003), amparado num discurso de "crise". A submissão do país a uma orientação macroeconômica externa ficou bem nítida com a política social direcionada a uma prática apenas focalista e precária no enfrentamento da "questão social". Enquanto o desemprego estrutural e o empobrecimento da população se ampliaram em níveis alarmantes, intensificando a ocorrência de condições de trabalho precarizadas e sem vínculo empregatício, a ação reguladora do Estado ia diminuindo, passando a estimular a solidariedade e construindo modalidades de parcerias no que era para ser da sua responsabilidade para com o social.

Assim, "recrutado" pelo próprio Estado no processo de contrarreforma, o "terceiro setor" é chamado para intervir na "questão social", por meio do programa de publicização e, particularmente pelo programa Comunidade Solidária. $\mathrm{O}$ "terceiro setor" apresenta-se como um agente capaz de deslanchar uma "mudança social", devido à sua capacidade de articulação, por ser um espaço democrático de mobilização comunitária e por ser também, apenas no nível do discurso, apolítico e aclassista, um "virtuoso". Mas, embora queira mostrar-se neutro, seu discurso de classe já foi desvelado (cf. Montaño, 2005) e é fato que seu compromisso com a classe dominante não faz parte de conjecturas. Num contexto histórico de ações paliativas e pontuais, a iniciativa privada foi incentivada pelo Estado a atuar no campo da prestação de serviços sociais.

No entanto, esse apelo à filantropia não é novidade no Brasil. A parceria entre Estado e sociedade civil já vem sendo costurada desde a década de 1930 (cf. Mestriner, 2005) e intensificada ao longo dos anos, oscilando entre ampliações e retrações. Realizando atendimentos que, a priori, seriam responsabilidades do Estado, a iniciativa privada reforça o discurso da ineficiência governamental - mesmo que seu financiamento muitas vezes seja proveniente dele. Assim, o "terceiro setor" (que juntou num mesmo pacote conceitual ONGs, movimentos religiosos, associações de moradores e filantropia empresarial, só para citar alguns) passa a executar ações sociais, fortalecendo uma postura 
clientelista nos atendimentos. Dessa forma o enfrentamento da "questão social" por meio da (re)filantropia e do terceiro setor se ampliou. Ao tornarem-se "parceiros" do poder público para a implantação e gestão de programas e projetos sociais, consolidam uma transferência de responsabilidades para a iniciativa privada no campo do investimento social, que, na verdade, seria uma atribuição constitucional do Estado brasileiro em todos os níveis de governo. Passou a ser um canal onde as demandas sociais resultantes da "questão social" podem ser absorvidas, desarticuladas, pulverizadas e transmutadas em "questões sociais", esvaziando sua origem nas contradições de classe, buscando respaldo no discurso da solidariedade e munido de uma legitimidade outorgada pela sociedade e pelo financiamento do Estado e/ou de empresas.

Valendo-se desse chamamento governamental, desde então a filantropia empresarial (ou neofilantropia empresarial) vai ganhando visibilidade como um agente "alternativo" capaz de absorver e atender demandas na área social (assistência social, infância e juventude, meio ambiente, direitos humanos, cultura etc.). Sua atuação se expande desde o financiamento de ONGs, parcerias com associações de moradores até a criação e a manutenção de fundações sociais, numa estratégia de gestão empresarial, conhecida atualmente como "responsabilidade social empresarial" (RSE). Para isso, podem contar até com o auxílio governamental, via parcerias, tendo as ONGs como "pontes" e/ou via deduções de impostos devidos ao Estado, respaldadas por leis federais. Dentre elas, destacamos a Lei de Incentivo à Cultura, em que as empresas investidoras em projetos culturais podem abater 5\% do imposto de renda devido ao fisco e, ainda, há a possibilidade de doação de até $1 \%$ do imposto de renda devido ${ }^{1}$ no caso de pessoa jurídica - para o Fundo para a Infância e Adolescência.

Por sua vez, as organizações que compõem o "terceiro setor" têm se aprimorado para buscar financiamentos junto a essas empresas, firmando parcerias e até se "adequando" aos seus interesses para atraí-las. Com a ampliação das ações sociais empresariais, dessa vez de forma sistemática — não mais restrita a doações de alimentos para creches ou asilos no Natal ou ao atendimento de seus funcionários (empréstimos internos, planos de saúde etc.), abre-se um campo potencial para a atuação do assistente social, na chamada "responsabilidade social das empresas".

1. Para pessoas físicas, a porcentagem de doação, com desconto no imposto de renda devido, é de até $6 \%$. 
Essa demanda pode ser considerada nova (ou renovada), pois se diferencia das tradicionais demandas para a profissão no âmbito da empresa - antes, basicamente voltadas para o público interno - , funcionários e suas famílias. Mas como o Serviço Social vem se posicionando frente a essa demanda? Que discursos os profissionais vêm reproduzindo? Existe uma adesão ideológica à responsabilidade social também dentro da categoria? Em caso afirmativo, em que nível?

Essas e outras inquietações nos levaram a empreender uma busca entre as produções teóricas acerca desse tema no Serviço Social, mas sem perder de vista a estrutura social e econômica na qual estamos inseridos e os projetos de sociedade em disputa neste contexto. Essas produções teóricas nortearam a pesquisa que realizamos junto à revista Serviço Social \& Sociedade e também nos artigos apresentados no $10^{\circ}, 11^{\circ}$ e $12^{\circ} \mathrm{CBAS}$, o fórum mais amplo de discussão das tendências presentes na categoria profissional. Mas, antes de apresentarmos os resultados da pesquisa propriamente dita, gostaríamos de compartilhar o diálogo que estabelecemos com as produções de alguns autores que trouxeram grandes contribuições para o debate sobre a responsabilidade social das empresas e que referenciaram teoricamente nossa inserção na pesquisa.

César em sua tese de doutorado, já no título deixa claro qual seu argumento principal - Empresa-cidadã: uma estratégia de hegemonia. A RSE, para a autora, resulta de um momento de maior organização do empresariado, que busca intervir na sociedade. Indaga-se se está em curso no país, desde os anos 1990, uma nova “cultura empresarial”, pautada na concepção de cidadania:

Parece haver, princípio, uma "concordância geral", no meio empresarial, de que o exercício da cidadania alavanca um processo histórico de mudanças rumo a uma sociedade com igualdade e justiça social, pois cada cidadão indiferenciado abandona a postura passiva de "ficar esperando por uma ação do Estado" e toma para si, por meio da solidariedade e da ajuda mútua, a responsabilidade de zelar pelo bem comum, semeando um futuro melhor para a coletividade, num presente sem conflitos e lutas de classe (César, 2005, p. 217-18).

Afirma também que o empresariado inaugura práticas renovadas de intervenção social, mesclando o "velho" e o "novo", uma vez que a utilização de mecanismos de controle da classe trabalhadora (coerção e consenso), que objetivam facilitar a exploração da mão de obra, possibilitando assim a acumula- 
ção de capital, não é um assunto novo no sistema capitalista. Mas apresenta um discurso renovado, uma vez que neste momento a balança empresarial está pendendo para o consenso, quando em outros momentos históricos a característica principal era a coerção como forma de controle da classe trabalhadora. Essa busca pelo consenso está presente nos discursos favoráveis à atuação privada nos atendimentos sociais como forma de ajudar o Estado, o qual já não conseguiria dar conta das mazelas sociais devido a uma crise financeira, a uma burocracia excessiva, aliada a altos índices de desemprego, a uma miséria crescente e à violência, que se tornou um problema crônico. Assim, conforme o discurso dos empresários, seria necessária a participação de todos para a diminuição dessas "desigualdades sociais". Aí reside o discurso do consenso, ao se declarar que todos têm sua parcela individual de responsabilidade e que devem atuar juntos para o "bem comum". Mas é essencial destacar que a RSE, enquanto estratégia de acumulação, se apoia em discursos de "cidadania empresarial", mas está comprometida com seus objetivos reais que aparecem mascarados por "intenções humanísticas" e pretensamente desinteressadas financeiramente.

Montaño argumenta que nesse momento ocorre o que chama de "fetiche da doação". Consideramos essa análise central, pois desmistifica a tão apregoada "boa vontade" do empresariado e sua "sensibilidade" frente aos "problemas sociais":

Em primeiro lugar, uma atividade verdadeiramente rentável transmutada em aparente "doação". Em segundo lugar, uma "doação" provinda supostamente de uma instituição (empresarial) e de uma classe (a burguesia), que, no entanto, no fundo, provém da sociedade (dos trabalhadores) e/ou do Estado - diretamente da sociedade, quando tal "doação" redunda em maiores vendas e preços, portanto, maiores lucros para a empresa "doadora" (que compensam e ampliam a "doação"); do Estado (e indiretamente da população pagadora de impostos), por meio de subvenções, isenções de impostos (renúncia fiscal) etc. Assim, o que parece ser "doação" do capital não é redistribuição de mais-valia, mas, na verdade, atividade lucrativa (Montaño, 2005, p. 209-10)

Os empresários incentivam um discurso da necessidade de um "pacto entre as classes", tendo em vista que a "crise" está posta, restaria às classes sociais formar uma "aliança" para sua superação. ${ }^{2}$

2. Sobre o enganador discurso de "crise", cf. Mota (2005). 
César (2005) ressalta que pode parecer estranho, ou paradoxal, que o discurso da responsabilidade social ganhe fôlego justamente quando "as empresas perdem uma das principais funções consideradas integradoras na sociedade moderna - geração de postos de trabalho - tal fato se articula com os valores próprios de um sistema que se transmuda, mas que mantém a mesma coerência interna de dominação e legitimação" (p. 297). A partir do raciocínio da autora, é possível dizer que, num momento do capital em que qualidade dos produtos e preços competitivos são um ponto de partida para permanecer no mercado, as empresas veem como alternativa para agregar valor à sua marca (tornando-a reconhecida e respeitada) o investimento em práticas de responsabilidade social.

Beghin, no ensaio publicado em 2005, A filantropia empresarial: nem caridade, nem direito, ressalta que as empresas vêm buscando alcançar legitimação social combatendo, pelo menos em discurso, as mazelas sociais causadas por elas mesmas, mas sem admitir isso, culpando uma "crise" virtual e genérica.

[...] o ativismo social empresarial tem relação direta com a reestruturação produtiva que vem ocorrendo no país nos últimos vinte anos. Essa reestruturação tem contribuído para dramatizar a questão social, e o setor privado lucrativo tem procurado suas próprias respostas para enfrentar esse crescente "desequilíbrio social". Essas respostas (i.e., captura da subjetividade operária, marketing social, desmanche das referências públicas) se ancoram na crítica à inoperância do Estado e das instituições políticas em cumprir sua responsabilidade social e na aposta de uma nova contratualidade não mais baseada nos direitos sociais. Elas ganham terreno e se legitimam na medida em que organizações da sociedade passam a reivindicar uma autonomia civil que, ao não se conformar numa alternativa política, contribuem para fragilizar o Estado democrático e, consequentemente, para retirar da arena política e pública os conflitos distributivos e a demanda coletiva por cidadania e igualdade. (Beghin, 2005, p. 42)

Beghin também insere a filantropia empresarial em duas frentes. A perspectiva caritativa seria basicamente assistencialista, culpabilizando o Estado pelos "problemas sociais". Para essa vertente, os "pobres" assim como as crianças estão numa condição de "menor", não tendo "capacidade de se conduzir por si mesmos. Assim, uma política moral é necessária na medida que está voltada a grupos em situação de minoridade. A infantilização do pobre e a valorização da criança são veículos desse tipo de tutela moral" (2005, p. 52). É caracterizada por ajudas, doações esporádicas feitas diretamente às comunidades ou pessoas 
pobres que se localizam no entorno das empresas. Por causa dessas características, muitos empresários "progressistas" rejeitam o rótulo de que realizam filantropia, pois buscam se manter distantes do estigma da caridade, que remete a um compromisso vinculado à religião. Utilizam as expressões "filantropia estratégica" e "filantropia transformadora", buscando resguardar uma mudança de visão frente às práticas tradicionais. Já a neofilantropia empresarial tem uma abordagem mais preventiva dos "problemas sociais". É calçada por um discurso baseado em conceitos como ética e cidadania, participação e parceria, mas ainda representa uma modalidade de intervenção reguladora da "pobreza". Estado e sociedade devem trabalhar em parceria para amenizar a "exclusão social". "Busca gerenciar os conflitos sociais pelo apelo a obrigações morais e éticas, retirando da arena política e pública os conflitos distributivos e a demanda coletiva por cidadania e igualdade" (Beghin, 2005, p. 55). Tem como características/objetivos principais: o incentivo à educação como meio de aumentar "a competitividade econômica nacional" e facilitar as "condições de inserção do país na nova ordem mundial" (Idem, p. 56), seguindo uma lógica de eficiência. Esse ativismo é divulgado pelo marketing social, onde ganha centralidade a figura do "cidadão consumidor" e suas preocupações com as desigualdades sociais e um desenvolvimento sustentável; o discurso da "parceria" e o comprometimento com uma "causa".

Sob a proteção deste termo [parceria], aparentemente "inofensivo", podem ser ocultadas propostas de transferência de responsabilidades, de delegação de poder político na direção do setor privado - lucrativo ou não —, de subordinação a uma lógica colonizadora que aprisiona o atendimento em métodos de intervenção tecnocráticos e orientados exclusivamente pela busca da eficiência" (Beghin, 2005, p. 61; grifo nosso)

Mas a autora deixa claro que embora a intervenção da neofilantropia empresarial queira se mostrar diferente da filantropia caritativa, na sua essência tem o mesmo objetivo moralizador que busca controlar a miséria, porém vez baseando-se na "moral da responsabilidade".

Kameyama (2004), no texto "Ética empresarial”, analisa como os princípios éticos universais vêm sendo utilizados para garantir competitividade e gerar lucro para o empresariado. Sob um discurso de um comportamento ético e responsável, as empresas vão desenhando uma nova estratégia. Argumenta que, 
a princípio, a lógica presente na responsabilidade social pode parecer incompatível "na paisagem capitalista", uma vez que seria resultante de pressões externas de movimentos sociais por cidadania, direitos dos trabalhadores, entre outros. Mas a autora afirma também que a empresa

ao conciliar o "lucro com ética", obtém ganhos tangíveis [...], sob a forma de fatores que agregam valor, reduzem custos e trazem aumento de competitividade, tais como melhoria da imagem institucional, criação de um ambiente interno e externo favorável, estímulos financeiros para a melhoria e inovações nos processos de produção, incremento da demanda por produtos, serviços e marcas, ganhos de participação de mercados e diminuição de instabilidade institucional e políticas locais, dentre outros" (Kameyama, 2004, p. 159).

Assim, segundo ela, essa postura ética presente no discurso da RSE é apenas instrumental, com propósitos meramente calculistas e flexíveis. Faz ainda uma abordagem da ética presente na responsabilidade social em duas vertentes: utilitarista e de egoísmo ético. A abordagem utilitarista, cuja matriz é a moral liberal (Locke), "parte do pressuposto de que cada indivíduo é naturalmente um ser social, pois não existe indivíduo independente, mas somente indivíduos associados em sociedades" (Kameyama, 2004, p. 160). Já o egoísmo ético seria baseado na seguinte premissa: "cada um deve agir de acordo com seu interesse pessoal, promovendo, portanto, aquilo que é bom ou vantajoso para si” (Idem, p. 161). Ou seja, a responsabilidade social das empresas está associada e esse princípio. Segundo a autora, a moral tem, com certeza, um caráter de classe nessa estrutura que abriga classes antagônicas. Mas alerta que a responsabilidade social das empresas se destaca pelo seu objetivo econômico, "na medida em que a economia é regida, antes de mais nada, pela lei do máximo lucro, e essa lei gera uma moral própria" (Kameyama, 2004, p. 162).

Neves e Sant'Anna (2005) ao discutirem as novas estratégias do capital, ressaltam o papel dos aparelhos privados de hegemonia como disseminadores de ideias como caridade, ajuda mútua, particularizando e pulverizando a "questão social" em situações aparentemente isoladas, individuais, "mantendo fora de pauta de discussões e ações sociais as contradições concretas do atual projeto societário" (p. 32).

Assim, consideramos que dessa vez joga-se de forma inescrupulosa com o componente emocional existente no ser humano da solidariedade, da compai- 
xão pelo empobrecido/"miserável" ou mesmo de culpa pela desigualdade social — que, por sua vez, estão ligados a uma religiosidade ou formação moral, levando-o enquanto "cidadão-consumidor" a escolher produtos "cuja parte das vendas" seria direcionada a alguma "causa", à diminuição de algum tipo de sofrimento.

$\mathrm{O}$ apelo à responsabilidade social de cada indivíduo, grupo ou comunidade, ponto focal da ideologia burguesa no atual processo de ocidentalização, constitui-se em importante estratégia de minimização dos efeitos da superexploração a qual está submetida boa parcela da classe trabalhadora mundial em consequência dos efeitos do desemprego estrutural e dos processos de precarização das relações de trabalho. Contraditoriamente, constitui-se também em importante mecanismo mobilizador em uma sociedade que a caridade representa, desde as origens. (Neves e Sant'Anna, 2005, p. 38)

O marketing em torno da RSE também pode estimular uma solidariedade forçada pelo "medo de se tornar a próxima vítima" de um atingido pela "desigualdade social". Buscando reforçar sutilmente esses sentimentos de penalização, culpa ou medo, os maestros da RSE se esforçam para incorporar a mídia como público interessado (stakehold) e torná-la multiplicadora de seu discurso, visando à adesão ideológica. Dois exemplos claros dessa tentativa foram as publicações: Conceitos básicos e indicadores de responsabilidade social empresarial, do Instituto Ethos direcionada aos jornalistas; e uma edição especial da revista Veja, o Guia para se fazer o bem, principalmente no artigo "Os primeiros passos de quem pretende arregaçar as mangas e trabalhar algumas horas por semana pelo outro".

Martins (2005) no artigo "Estratégias burguesas para obtenção do consenso nos anos de liberalismo da terceira via", faz uma observação acerca desta estratégia: “[...] é possível afirmar que o 'lucro' e a 'responsabilidade social empresarial' se relacionam positivamente não como ações voltadas à obtenção de resultados imediatos, mas como medidas de alcance de longo prazo, inseridas em um processo internacional de recuperação da hegemonia burguesa" (p. 157). Assim, podemos dizer que o capital mudou a estratégia para continuar igualmente no controle. Houve a necessidade estratégica de o discurso do capital enfatizar o consenso, o "pacto entre as classes".

A RSE adotou discursos de defesa da cidadania, da democracia, da participação social, da solidariedade e da parceria para o enfrentamento da "questão 
social" como uma estratégia ideológica, visando facilitar a ampliação de seus níveis de acumulação. Assim, o termo cidadania foi banalizado e aparece de forma genérica em seu discurso, tanto como democracia e solidariedade. A expressão "cidadania empresarial", largamente utilizada para demonstrar as ações de preocupação social dos empresários, serve apenas para legitimar seu discurso, uma vez que a palavra cidadania assume grande peso na cultura brasileira, dadas as lutas e resistências por seu alcance, principalmente na história mais recente do país. Outro termo caro à memória histórica recente do país é democracia, enquanto conquista social e também política, que foi apropriado e esvaziado de seu conteúdo, mas mantido no discurso num nível simbólico. O preocupante é que esse discurso de "consenso entre as classes para o bem de todos" neste momento de "crise do Estado", vem convencendo a muitos, até mesmo dentro da categoria profissional.

\section{Reflexões acerca da delimitação do objeto e dos resultados da pesquisa}

Nosso objetivo era analisar se/ou de que forma a literatura do Serviço Social tem se debruçado sobre tema tão atual e polêmico — a chamada "responsabilidade social das empresas" (RSE) — que chama a atenção pelo volume de recursos investidos (cerca de R \$ 4,5 bilhões em 2005) ${ }^{3}$ e cujos projetos sociais e fundações vêm ampliando sua presença no cotidiano profissional, inclusive fazendo parte de conselhos de direitos e disputando os escassos recursos disponibilizados para a assistência social, por exemplo. O instrumento utilizado para a coleta dos dados foi a pesquisa bibliográfica com análise de conteúdo (teórica), uma vez que acreditamos ser esse o que mais atenderia aos nossos objetivos.

Por esta razão, elegemos como fontes de pesquisa: a revista Serviço Social \& Sociedade e os três últimos Congressos Brasileiros de Assistentes Sociais (CBAS). A revista Serviço Social \& Sociedade foi escolhida por ser um dos periódicos mais respeitados pela categoria profissional por sua seriedade, em cerca de trinta anos de existência. É também a principal revista voltada para a formação e capacitação de profissionais de Serviço Social no país. Mas, devido à amplitude deste material foi necessário realizarmos um recorte temporal

3. Dados do Instituto de Pesquisas Econômicas Aplicadas (Ipea). 
(apenas para fins didáticos) nos últimos dez anos, abarcando de 1997 até setembro de 2007. Porém esse tempo limítrofe foi pré-selecionado, levando-se em conta o avanço das políticas neoliberais no Brasil a partir de meados dos anos 1990 e a intensificação das políticas e práticas de responsabilidade social no país a partir da mesma época. Já a escolha dos três últimos CBAS (10, 11 e 12), também como fonte de pesquisa, justifica-se pelo fato de que buscávamos saber como os assistentes sociais, que muitas vezes veem nesse Congresso a possibilidade de apresentar suas pesquisas de campo e relatos de experiências laborativas, estão se posicionando em seu cotidiano profissional e que discursos estão reproduzindo, intencionalmente ou não. A partir desta delimitação, passamos a selecionar quais artigos tratavam especificamente da responsabilidade social das empresas, filantropia empresarial e/ou balanço social. Na sequência, apresentamos os resultados analíticos da pesquisa.

\subsection{Como a responsabilidade social das empresas aparece na revista Serviço Social \& Sociedade}

Foram pesquisadas todas as revistas desde 1997 até setembro de 2007, inclusive os números especiais temáticos publicados no período, totalizando 42 . Assim, chegamos a apenas três publicações que tratavam especificamente do tema, o que representa 7\% do total em dez anos — novembro/1998, julho/2004 e uma publicação especial em setembro/2007.

Mas, o número reduzido de artigos não deixa a desejar sob o aspecto do conteúdo, tal foram os resultados que encontramos e que são apresentados, de forma sintética, a seguir. No primeiro deles, publicado na revista n. 58, tendo como título "O empresariado, a filantropia e a questão social" (1998), Rico apresenta a filantropia empresarial como uma novidade que vem crescendo no Brasil. Faz alguns questionamentos sobre os objetivos e consequências desse investimento dos empresários em programas sociais. Dentre esses questionamentos, destacamos a seguinte pergunta: “[...], serão os empresários melhores gerentes de programas sociais e, portanto, atingirão resultados mais expressivos?" (p. 26). Após a leitura do texto, é possível dizer que a tônica da análise de Rico (1998) caminha para responder de forma afirmativa a essa questão. Parece desconsiderar em sua análise que o Estado mínimo foi uma opção política, social e econômica em meados dos anos 1990, não tendo nada de inevitá- 
vel ou obrigatória. Mas reflete, sim, um projeto de país cujo compromisso é única e exclusivamente com o capital. Supervaloriza a capacidade de intervenção social do terceiro setor, especialmente da filantropia empresarial. Observem as seguintes colocações da autora:

Essa "dificuldade" de investimento em programas sociais que efetivamente enfrentem a miséria e a exclusão social, "obriga" o Estado a estabelecer parcerias com a sociedade civil. A escassez de recursos fez parte de um cenário que praticamente coloca a responsabilidade civil do cidadão e do empresário como indispensáveis ao enfrentamento da questão social" (Rico, 1998, p. 31; grifo nosso).

Mas o que surpreende nesse texto é que a autora possui o conhecimento sobre as categorias necessárias, a princípio, pelo menos, para realizar a análise das consequências do neoliberalismo para a sociedade. Discorre, inclusive, sobre a flexibilização das relações de produção. Cita a utilização do "fundo público" para promover a acumulação de capital e também para o financiamento da reprodução da força de trabalho. No entanto, parece que sua análise não conseguiu transcender o imediato, o aparente, ou tenta ser otimista, buscando resgatar na filantropia empresarial um inexistente quê de solidariedade e cidadania legítimas: "Entende-se que a empresa cidadã amplie sua atenção para além dos seus próprios muros e assuma compromissos mais efetivos na solução dos problemas da sociedade na qual está inserida (Rico, 1998, p. 38). No nosso entender, a autora não conseguiu articular em sua análise a estrutura capitalista na qual estamos inseridos bem como as estratégias e a capacidade do capital para transmutar-se, buscando garantir seus níveis de acumulação, com os objetivos reais da filantropia empresarial nesse contexto. No entanto, Rico (1998) tem o mérito de perceber que algo "novo ou renovado" estava acontecendo no âmbito empresarial - a filantropia empresarial, e de ter trazido esta discussão para a categoria profissional, em nível nacional, através da Revista.

O segundo artigo, publicado por Góis et al. em 2004, na revista n. 78, sob o título "Responsabilidade social empresarial e solidariedade: uma análise dos discursos dos seus atores", se propõe a discutir as características presentes no discurso dos empresários brasileiros frente à RSE. Inicialmente, discorrem sobre a atuação, ao longo da história brasileira, dos empresários frente à questão social e suas visões em relação à pobreza, desde o final do século XIX e chegando aos anos 1990. Ressaltam que, apesar de seus objetivos mercantis, é 
possível apresentar exemplos de "atitudes que podem expressar uma postura socialmente solidária, mostrando o reconhecimento de certos elos de solidariedade não é estranho a seus interesses" (Cappelin apud Góis et al., 2004, p. 83). Ao falarem do contexto do país nos anos 1990, destacam que, ao contrário dos trabalhadores, os empresários não diminuíram sua capacidade de organização enquanto categoria nesse período. Destacam também como questão relevante, para a expansão da responsabilidade social no país, as mudanças ideológicas e de condução política que causaram a regressão dos direitos sociais.

Ao enfatizar a necessidade de maior participação da sociedade no enfrentamento da pobreza, esta discussão deu passagem à expansão da ideia de parceria como estratégia privilegiada para a produção de um novo padrão de relacionamento entre o mercado, o Estado e as organizações da sociedade civil. Foi nesse movimento que avançou a incorporação, por parte do mercado, da noção de responsabilidade social, materializada na montagem de fundações e associações [...]. (Góis et al., 2004, p. 86)

No grupo de empresários pesquisado por Góis et al. (2004) a solidariedade é apontada como a mola propulsora que impulsiona o empresariado. Assim, solidariedade se apresentaria como mais politicamente correto do que o termo caridade, já que existe a necessidade de os empresários adequarem o discurso aos novos tempos. Ressaltam a necessidade de construção de um "novo pacto social", com a responsabilização de todos, trabalhando de forma cooperativa. Esse "novo pacto social" incluiria também mudanças na legislação trabalhista, onde os empresários consideram que existam "resquícios paternalistas", que precisam ser suprimidos, se adequando ao novo século. Outro ponto ressaltado pelos autores se refere às críticas feitas pelos empresários à incapacidade de gestão social e econômica do Estado, seguidas da celebração da filantropia empresarial e do voluntariado, como uma opção:

Atuando de forma complementar ao Estado, [as OSCs] realizam eficazes programas de saúde, educação, cultura, esportes, reintegração social e iniciação profissional. Essas organizações estão mais próximas das ruas e dos problemas da comunidade, foiçando de maneira mais precisa as questões a serem sanadas. Além disso, têm o paradigma empresarial do compromisso com os resultados. (Altenfelder apud Góis et al., 2004, p. 99) 
Assim, baseando-se numa lógica numérica, os empresários buscam trazer os paradigmas gerenciais de eficiência e eficácia para o investimento social privado. Particularmente no item 6, que trata "Do discurso à prática", apresentam algumas contradições presentes nos discursos analisados na pesquisa: o discurso não condiz com a prática em relação à gestão e avaliação das ações sociais; são frequentes as sobreposições de ações sociais numa mesma região, além de pedidos de subsídios estatais para as ações; o tom do discurso é o da busca pela cidadania, porém as práticas de defesa de direitos não aparecem como foco de atuação das empresas pesquisadas (cf. p. 104). Após acompanhar a linha de argumentação apresentada pelos autores ao longo de todo texto, diríamos que, em relação ao item "Comentário Final”, cabe uma dúvida, mais do que apenas um desconforto de análise. Embora Góis et al. (2004), no item 6, tenham dito, entre outras coisas, que: "Tudo isso revela a existência de um continuum de interesses, no qual a linha divisória entre o que no discurso em causa é definido como uma prática corporativa social genuína e a busca de mais lucros é bastante tênue (Góis et al., 2004, p. 104), no final, teceram um comentário extremamente otimista quanto às intenções do empresariado com a responsabilidade social, como se os autores não tivessem conhecimento dos resultados apresentados por sua própria pesquisa. Porém, devido à ambiguidade das argumentações apresentadas entre o restante do texto e o item 7 (Comentário final), transcrevemos, a seguir o parágrafo final do artigo:

É por causa desse conjunto de questões, dúvidas e possibilidades que devemos aprofundar o conhecimento sobre o pensamento dos dirigentes empresariais: dada sua influência nos processos decisórios, eles têm uma inquestionável atuação na formulação e implementação de políticas sociais, as quais terão maiores chances de ser bem-sucedidas se pudermos contar com seu apoio. Assim, ao sabermos o que o empresariado pensa, podemos elaborar também estratégias mais eficazes para obter o seu engajamento mais efetivo nas lutas sociais do país. (Góis et al., 2004, p. 105; grifos nossos)

Lutas sociais? Contra quem, se para os autores todos (Estado, empresários e sociedade) precisam estar do mesmo lado? Onde ficam os conflitos de classe existentes na estrutura social, política e econômica em que vivemos? No final do texto, tudo isso foi desconsiderado em detrimento da necessidade de uma suposta solidariedade de classes, de uma aliança em torno da empresa para o 
enfrentamento da "questão social". Sabemos que a história está sendo escrita a cada momento e que sempre existe a possibilidade de mudanças ou transformações, que são construídas na prática cotidiana. Porém no comentário final do presente artigo, partindo da própria análise a que se propuseram, os argumentos e as inconsistências do discurso do empresariado que apresentaram, não caberia, a essa altura, por parte dos autores, uma fala de coesão social para o bem comum.

Já no artigo publicado na revista Serviço Social \& Sociedade n. 91, cujo título é "Responsabilidade social empresarial e a mercantilização da solidariedade", Groppo (2007) descreve os padrões de intervenção social no Brasil desde a década de 1970 e chega ao governo Lula, que manteve a parceria existente no governo anterior (FHC) com o "terceiro setor" e tem no Programa Bolsa Família “um instrumento 'permitido' pelos teóricos do neoliberalismo para o combate à miséria" (p. 148). Ressalta o paradoxo presente entre a "irresponsabilidade social" do capital (demissões, subcontratações, automação etc.) e o discurso da responsabilidade social. Mas, segundo ele essa contradição é apenas aparente; "Ela é um veículo para outros fins: os mesmos que as tornam, no que é mais crucial em suas atividades — a produção e os serviços — socialmente irresponsáveis, a saber: o lucro e a acumulação" (p. 149). Aponta ainda o que chama de "irresponsabilidade semântica" dos termos apropriados e manipulados pelo discurso da responsabilidade social:

Na sua junção, os interesses e necessidades sociais a satisfazer pelo exercício gratuito da solidariedade (o "valor de uso") tornam-se embalagens a adocicar o real a procura de valores de troca pela ostentação dessa solidariedade. [...] Os donos do poder político e econômico, ao longo dos anos 90 e início do atual século, se portaram como se fossem os "progressistas" da vez e acusaram os defensores das camadas populares e de projetos alternativos ao capitalismo como "conservadores", numa curiosa inversão dos significados atuais de "esquerda" e "direita". (Groppo, 2007, p. 150-1)

Segundo sua análise, na RSE a solidariedade foi transformada em mercadoria, ou seja, pode ser quantificada. Seu valor de troca passa a ser medido com o auxílio dos "indicadores", que buscam mensurar o quanto as empresas seriam "socialmente responsáveis". Para ele, a RSE constrói simulacros da solidariedade, deslegitima direitos sociais, tem uma intervenção nos efeitos sociais do 
neoliberalismo socorrendo "os excluídos sem permitir sua real integração — o que só seria possível com a transformação profunda do sistema socioeconômico" (Idem, p. 158); confunde o que seria público ou privado.

2.2 Como a responsabilidade social das empresas aparece nos três últimos Congressos Brasileiros de Assistentes Sociais (CBAS)

Em que pese aqui nosso respeito para com o esforço teórico e de pesquisa empreendido pelos participantes das sessões temáticas com artigos, que buscavam fazer um trabalho com fundamentação, seja na tendência crítica ou na tendência conservadora/neoconservadora/eclética, não pode ser negado que dentro da categoria profissional também existem projetos de sociedade em disputa e que são reproduzidos nos discursos. E isso, mais do que nunca, ficou claro também nos artigos apresentados sobre a RSE nessas três últimas edições do CBAS:

- $10^{\circ}$ Congresso Brasileiro de Assistentes Sociais: realizado no Rio de Janeiro, em outubro de 2001 , o $10^{\circ}$ CBAS tinha como tema maior "Trabalho, direitos e democracia: assistentes sociais contra a desigualdade".

- $11^{\circ}$ Congresso Brasileiro de Assistentes Sociais: foi realizado na cidade de Fortaleza (CE), em outubro de 2004. Tinha como tema geral "O Serviço Social e a esfera pública no Brasil: o desafio de construir, afirmar e consolidar direitos".

- $12^{\circ}$ Congresso Brasileiro de Assistentes Sociais: aconteceu do período compreendido entre 28 de outubro e 2 de novembro de 2007, na cidade de Foz do Iguaçu (PR). Seu tema central era "A questão social na América Latina: ofensiva capitalista, resistência de classe e Serviço Social”.

Após a pesquisa, é possível dizer que o Serviço Social vem aos poucos se debruçando sobre o debate a respeito da filantropia empresarial/responsabilidade social das empresas, principalmente quando observado o volume crescente de artigos apresentados desde o $10^{\circ}$ até o $12^{\circ} \mathrm{CBAS}$, independente da vinculação teórica de cada autor. 
No $10^{\circ} \mathrm{CBAS}$, o assunto filantropia empresarial apareceu em sessões temáticas bastante variadas (relações de trabalho e Serviço Social: dois artigos; Seguridade Social — assistência: um artigo; Seguridade Social — previdência e geral: um artigo; e Trabalho, direitos e democracia: um artigo). ${ }^{4}$ Também recebeu várias nomenclaturas, sendo chamada desde cidadania empresarial, responsabilidade social empresarial, empresa cidadã, filantropia empresarial, dentre outras. Já o $11^{\circ}$ CBAS contou com cerca de 1200 trabalhos inscritos, subdivididos em dezessete sessões temáticas, que tratavam dos mais variados temas dentro da atuação e formação profissional do assistente social. Mas a única sessão temática que apresentou artigos específicos sobre a responsabilidade social das empresas foi "Sociedade Civil e a construção da esfera pública: movimentos sociais, redes, ONGs e terceiro setor" (eixo temático 12). ${ }^{5}{ }^{6} \mathrm{O} 12^{\circ}$ CBAS contou com 1119 trabalhos inscritos, sendo 715 comunicações orais e 159 pôsteres aprovados para apresentação, distribuídos por quinze sessões temáticas. A sessão temática que registrou artigos sobre responsabilidade social empresarial/filantropia empresarial/balanço social foi "Questão social, trabalho, Estado e democracia". ${ }^{7}$ Fizemos graficamente uma comparação proporcional entre o número de artigos apresentados sobre responsabilidade social/filantropia empresarial, ao longo dos três últimos CBAS, organizados por tendências — que

4. O texto de Nogueira (2001), "Relações de trabalho e políticas sociais Empresariais: análise dos efeitos da reestruturação produtiva das indústrias do setor eletroeletrônico da Zona Franca de Manaus a partir de 90" aborda as políticas sociais empresariais, dentro de seus muros, sob o aspecto de sua redução ou extinção com as mudanças no mundo do trabalho, a partir dos anos 1980. Ou seja, apesar do título, não estaria incluída no foco de nossa pesquisa.

5. Faes e Rubião (2004) apresentaram o texto "Projeto Responsabilidade (sobre o) social" que trata da educação para preservação ambiental. Não aborda a filantropia empresarial, apesar de o título fazer esta sugestão.

6. No texto "Estado, sociedade civil e responsabilidade social: o 'terceiro setor' nesse contexto", Serra (2004) objetiva contribuir para o debate sobre o "terceiro setor", tendo em vista sua expansão a partir dos anos 1990. Mas cabe ressaltar que, apesar do título, a autora não se referiu especificamente no texto ao papel da RSE.

7. Apresentamos um artigo, sob o título "Sem fins lucrativos? Uma abordagem da 'Responsabilidade social empresarial' no Brasil", baseado nas primeiras considerações feitas durante a presente pesquisa. Discutimos a ampliação das ações sociais privadas no país a partir da década de 1990, acompanhando o processo de contrarreforma do Estado, enfatizando a RSE. Afirmamos que, mesmo que a RSE se apresente compromissada com a sociedade, esconde uma estratégia de acumulação de capital, utilizando discursos de preocupação social, de parcerias com o Estado e com ONGs e o próprio marketing social, visando sempre o lucro. 
chamamos de tendência crítica ou de tendência conservadora/neoconservadora/ eclética $^{8}$ — visando facilitar a análise e demonstrar as vinculações teóricas dos autores:

\section{GRÁFICO 1}

Vinculação teórica dos artigos apresentados nos três últimos CBAS

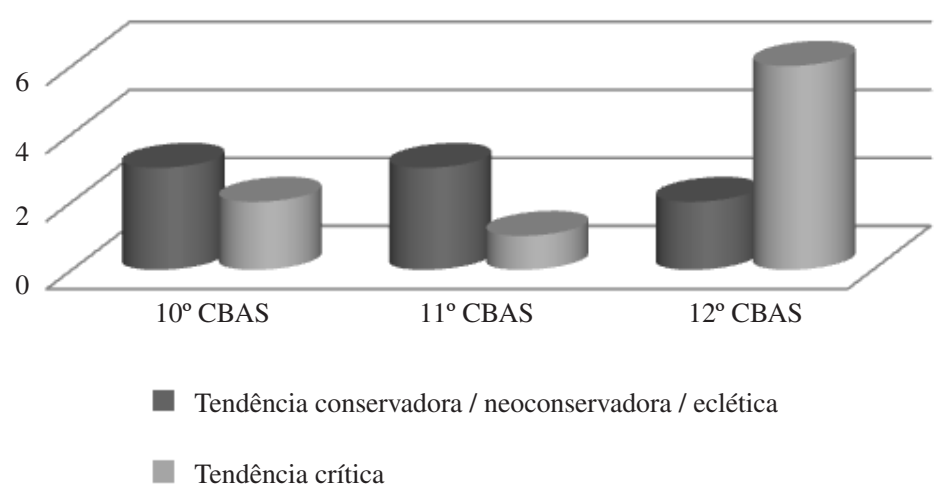

Ao final de três congressos foi possível verificar que cerca de $61 \%$ dos artigos que trataram da temática não se limitaram a reproduzir o discurso corrente sobre a RSE. Os resultados demonstraram um maior volume de artigos de tendência crítica, problematizando e discutindo as consequências da filantropia empresarial, aliado a um maior aprofundamento das análises. Outro aspecto verificado foi o aprimoramento da qualidade da discussão, com novos elementos de análise sendo apresentados, principalmente por uma parcela da tendência crítica, que tem percebido esse movimento estratégico do capital em busca da ampliação da acumulação, ao mesmo tempo em que procura construir o consenso em torno de seu projeto de exploração.

A partir daqui, faremos algumas ponderações sobre as similaridades dos discursos nos artigos, de acordo com a tendência de análise que se propuseram.

8. Optamos por chamar de conservadora/neoconservadora/eclética, por falta de uma nomenclatura que melhor as defina. 
Nosso objetivo é conjugar, em dois momentos, os discursos semelhantes para que seja possível ter uma dimensão mais nítida dos posicionamentos contrários ou favoráveis à responsabilidade social apresentados nos três últimos CBAS.

a) Comentários acerca dos artigos de tendência conservadora/neoconservadora/eclética

Esta tendência já vinha reproduzindo desde o $10^{\circ} \mathrm{CBAS}$ o discurso favorável à responsabilidade social das empresas posto pela mídia (via marketing social) e pelas publicações com grande força de convencimento, embora numa análise mais atenta de suas intenções os seus argumentos não se sustentem e nem seus resultados de gestão se mostrem "tão eficientes" quanto desejam. Dentre todos os textos analisados durante esta pesquisa, chamou nossa atenção algumas características presentes nos discursos dos autores (Vaz, 2001; Marques, 2001; Oliveira, E. M., 2001; Veronese e Muniz, 2004; Oliveira, C., 2004; Góis et al., 2004; Lima e Andrade, 2007; Schmidt e Suguihiro, 2007) que optaram por essa linha de análise conservadora/neoconservadora ou com características de ecletismo. Em muitos momentos encontramos afirmações bastante similares a esta: o "principal papel do assistente social é: ser um facilitador no acesso e compreensão das informações e conceitos apropriados da responsabilidade social e do papel cidadão das empresas que queiram se engajar na luta contra os problemas sociais de nosso país" (Oliveira, 2001, p. 5; grifos nossos).

Consideramos bastante preocupante sua utilização "parcial" de discursos ligados à tendência crítica. A maioria dos artigos pela maioria dos artigos da tendência conservadora/neoconservadora/eclética também faz uma análise de conjuntura e a relaciona com a estrutura. Contextualiza de forma "didática" o neoliberalismo, a reestruturação produtiva e as consequências desse modelo de produção - como o desemprego e a chamada "exclusão social" (expressão bastante usada por eles). No entanto, não relaciona as empresas como fundamentais para a criação da desigualdade social, do pauperismo e também de seu aprofundamento na realidade brasileira. E aponta as ações de responsabilidade social realizadas pelas empresas como um meio potencial e "alternativo" de superação da "desigualdade social".

Outro ponto que nos chamou a atenção foi a grande frequência nos textos da expressão "questões sociais", uma discussão que acreditávamos já ter sido superada pela categoria, pois a "questão social" é apenas uma, com refrações 
que se colocam no cotidiano e muitas vezes vem sendo enfrentada de forma paliativa, fragmentada e descontínua. Cabe aqui a explicação dada por Iamamoto, que já havia alertado sobre o equívoco teórico que é utilizar a expressão "questões sociais":

Por uma artimanha ideológica, elimina-se, no nível da análise, a dimensão coletiva da questão social, reduzindo-a a uma dificuldade do indivíduo. A pulverização da questão social, típica da ótica liberal, resulta na autonomização de suas múltiplas expressões — as várias "questões sociais" —, em detrimento da perspectiva de unidade. Impede assim de resgatar a origem da questão social imanente à organização social capitalista, o que não elide a necessidade de apreender as múltiplas expressões e formas concretas que assume (2001, p. 18).

Assim, não causa tanto espanto que a tendência conservadora/neoconservadora/eclética utilize a expressão "questões sociais", uma vez que ela remete a uma individualização e a uma pulverização no enfrentamento da "questão social", numa atitude de tentar esconder as contradições estruturais presentes e causadas pela sociedade capitalista.

Foi frequente também nos artigos a reprodução de um discurso de "crise do Estado" e o convite para um "pacto social pela solidariedade" em prol da diminuição da "exclusão social" é feito em várias conclusões dos textos. Muitos autores dessa tendência veem na filantropia empresarial um substituto do Estado na intervenção social e acreditam fielmente (pelo menos isso estava presente em suas argumentações) que a transposição da eficiência e da eficácia da racionalidade de mercado para as ações sociais, junto com os investimentos financeiros das empresas, seria a solução viável nesses "tempos de crise". Aderem ao modelo e ao discurso da RSE, reforçando uma imagem da "filantropia empresarial" como o agente capaz de realizar uma "mudança social", em que as desigualdades sociais possam ser reduzidas, ou depositam na empresa uma esperança de que a mesma seja uma alternativa para o enfrentamento dos "problemas sociais". ${ }^{9}$ Vários artigos empreenderam uma adesão ao movimento da RSE como praticamente um "ato de fé", sem fazer as mediações mínimas necessárias ao realizar sua análise. Outros autores chegam a propor "um pacto social" em torno da empresa, que foi apontada por alguns como o agente capaz

9. As aspas são para enfatizar as expressões utilizadas pelos autores. 
de intervir com sucesso na "questão social". Alguns até chamam a atenção para a necessidade de se obter "maior engajamento" por parte do empresariado nas "lutas sociais" do país, já que são detentores dos recursos financeiros. Isso sem nos ater aos autores que fazem praticamente uma defesa visceral de seus próprios empregos. Porém faz-se necessário demarcar que, ao contrário do discurso corrente, essas ações aparentemente "bem-intencionadas" não estão acima dos conflitos de classe. Suas ações têm intencionalidades e um nítido caráter de classe. O Estado ainda é uma arena de disputas de projetos societários, não um bloco hegemônico. Faz-se necessário realizar as mediações analíticas, políticas e ideológicas para não engrossar os discursos de "satanização" do Estado, de "virtuosidade" e "purismo" da sociedade civil e de "boa vontade" desinteressada e desprendimento financeiro por parte das empresas.

\section{b) Comentários acerca dos artigos de tendência crítica}

Os textos de tendência crítica sinalizam uma aproximação e amadurecimento dos autores (Garcia, 2001, 2004 e et al., 2007; Porto E Soares, 2001; Pfeifer, 2007; Leite e Albertasse, 2007; Amaral, 2007 e Mota et al., 2007), em relação às argumentações e análises críticas a respeito da RSE/filantropia empresarial/cidadania empresarial. Cabe destacar as contribuições de Garcia, que apresentou artigos sobre o tema desde o $10^{\circ} \mathrm{CBAS}$, sendo no $12^{\circ}$ Congresso escrito em parceria com Carvalho, Moreira, Menicke e Amaro. No artigo de 2004, Garcia toca num ponto central: por meio do marketing social, a solidariedade tem sido incentivada e também utilizada como forma de autoproteção, de autodefesa contra a ação violenta do "excluído", contribuindo para um movimento de discriminação do "pobre". Destaca também que, apesar da crítica feita pela filantropia empresarial à intervenção caritativa presente na filantropia tradicional, as ações sociais das empresas também podem refletir esse discurso caritativo/paternalista. $\mathrm{O}$ debate apresenta um posicionamento embasado teoricamente de modo substantivo e coerente, buscando desconstruir o conceito de responsabilidade social das empresas fomentado pela mídia, principalmente pelo marketing social e pelas publicações crescentes sobre o tema, que vem alardeando os benefícios e a eficiência da filantropia empresarial, ao mesmo tempo em que sataniza o atendimento estatal das demandas sociais.

Gostaríamos também de ressaltar um trecho do artigo "Balanço social: elementos de formação do consenso", onde Pfeifer (2007), a partir das reflexões 
sobre a categoria hegemonia e principalmente de um de seus elementos - o consenso - , utiliza a influência de Gramsci para demonstrar o que há por trás do discurso da RSE:

Auferindo a empresa capitalista uma inserção diferenciada na sociedade, pela sua vinculação a questões de interesse social, a Responsabilidade Social das empresas insere-se num processo que vem fortalecendo ou legitimando a ideia de um "capitalismo humanitário" ou do capitalismo como o "fim da história". Portanto, evidencia-se que a Responsabilidade Social das empresas insere-se como um dos componentes do processo através do qual se dá a hegemonia capitalista hoje, e mais especificamente, como um ingrediente do processo de construção de consensos em favor do projeto burguês. (Pfeifer, 2007, p. 7)

Já Mota et al. (2007), no artigo "A nova cultura empresarial nos marcos do capitalismo contemporâneo" situa as mudanças das práticas empresariais no campo social desde a década de 1970, quando ainda eram apenas internas, restritas aos empregados. Mas ressaltam que a mudança de estratégia desde então não significa uma ruptura com o passado, já que a nova cultura empresarial tem características de inovação, mas também de continuidade. Afirmam que as ações sociais das empresas não se constituem em reformas sociais. São, na verdade, conservadoras, mas com práticas renovadas, que objetivam minimizar as contradições, como analisa Mota et al. (2007, p. 5):

Constituem-se num meio para assegurar a adesão dos trabalhadores às organizações empresariais que se transformam em verdadeiros aparelhos privados de hegemonia sob os auspícios de seu reconhecimento social que se firma para além do ambiente interno de cada corporação. O que é subtraído no campo da exploração e precarização do trabalho é compensado no campo genérico da intervenção social.

Baseando-se num discurso de Estado mínimo, que necessita do auxílio de outros setores atuando como parceiros, inclusive as empresas, via responsabilidade social, vão se desenhando alianças de classe, onde "a marca registrada das ações do capital neste campo caracteriza-se por tratar a questão social e ambiental como 'externalidade' da dinâmica inerente ao processo de produção e reprodução social" (Mota et al., 2007, p. 5). Observamos também que a maioria dos artigos apresentados pela tendência crítica se reportou às contribuições de Mon- 
taño no texto "Das 'lógicas do Estado' às 'lógicas da sociedade civil': Estado e 'terceiro setor' em questão" e ainda, no livro Terceiro setor e questão social: crítica ao padrão emergente de intervenção social, que são referências para a categoria na discussão sobre o "terceiro setor" e seus desdobramentos. No entanto, essa discussão acerca da filantropia empresarial/RSE parece ainda estar longe do fim. Porém, neste momento, já se encontra reunido um maior volume de elementos conceituais para respaldar uma análise teórico-crítica mais profunda e abrangente. Para os autores de tendência crítica, a filantropia empresarial não tem condições de substituir o Estado no atendimento das demandas sociais. Em última instância, serve fielmente aos interesses neoliberais: atendimento de demandas sociais pela via do mercado e achatamento do Estado para o social, enquanto este último se amplia para interesses privados mercantis.

\section{Considerações finais}

O discurso de "crise do Estado" e de sua ineficiência de gestão se fortalece ao mesmo tempo em que é repassada para a sociedade, via solidariedade e filantropia, a responsabilidade pelo atendimento das demandas sociais resultantes da "questão social". Assim, se reforça o caráter excludente do modelo de sistema capitalista implantado no país onde o direito social vem sendo substituído, de forma cada vez mais ampla, pela benesse. A chamada "responsabilidade social das empresas" se insere nesse contexto exercendo um papel segmentador e segue na contramão dos direitos sociais conquistados pela classe trabalhadora.

Focaliza o atendimento das demandas sociais no campo do "não direito", da benesse, da filantropia. Sua glorificação pela sociedade e pelo próprio Estado só contribui para que se esvazie a percepção dos direitos sociais existentes e que podem ser acionados — inclusive judicialmente, quando violados ou negados pelas instituições públicas estatais.

Gostaríamos de ressaltar que isso não significa que o profissional deva recusar-se a ocupar esse espaço de atuação profissional. Afinal, enquanto trabalhador, necessita vender sua força de trabalho. Mas não deve também nutrir ilusões quanto à possibilidade de as práticas sociais das empresas serem a solução para o pauperismo em que se encontra grande parcela da população e nem deve se enganar, acreditando que o mercado está comprometido realmente com 
a superação da desigualdade social. Ao contrário do que alguns artigos da tendência conservadora/neoconservadora/eclética argumentaram, as fundações sociais das empresas e seus projetos de "cidadania empresarial" não têm condições de substituir os postos de trabalho fechados no âmbito estatal. Além disso, o vínculo empregatício com esses projetos é precário, flexível e, muitas vezes, temporário. O trabalho, embora tenha um discurso de construção da cidadania, se restringe a uma prática assistencialista, que busca o consenso entre classes antagônicas, ou mesmo de "enquadramento" ou cooptação do "usuário", já que nesse campo não existe espaço para "sujeitos de direito" - existem usuários de serviços privados. Nessas ações não existe nenhuma garantia de atendimento; o público-alvo é escolhido de acordo com a imagem que a empresa pretende passar aos consumidores; suas ações são paliativas e superficiais, já que as empresas precisam mostrar resultados rápidos para ganhar visibilidade e garantir seus lucros. Seus atendimentos, por serem privados, não se constituem em "direitos sociais", ao contrário do que ocorre no Estado. Estão inscritas no campo do "não direito", contribuem para o paternalismo nos atendimentos e para a refilantropização da assistência social - mesmo que seus adeptos rejeitem o rótulo da "filantropia" por ser facilmente associado com a caridade ou com igrejas de modo geral.

A tão divulgada "cidadania empresarial" se sustenta apenas no nível da propaganda, e isso fica bem nítido quando analisamos os discursos de seus defensores, nos quais em nenhum momento a concentração de renda existente na mão de uma minoria é colocada em discussão. Fala-se em "desigualdade social" e em "pobreza", mas nunca em redistribuição da renda e nem da riqueza produzida socialmente. As ações caritativas tradicionais não foram abandonadas. Foram revisitadas, revisadas e articuladas numa "filantropia estratégica", mesmo que apresente uma nova roupagem e ideologicamente tenha um alcance muito maior. Precisamos também estar atentos à utilização distorcida dos conceitos de democracia, solidariedade, cidadania e participação, presente nos discursos e nas publicações de defesa da "responsabilidade social empresarial" (ou filantropia empresarial ou cidadania empresarial).

Segundo Iamamoto (1998, p. 142), "a luta pela efetivação da democracia e cidadania é indissociável da ampliação progressiva da esfera pública”, ou seja, apesar do que tem sido apregoado pelas empresas, não há como construir e consolidar espaços democráticos recorrendo ao mercado, que tem uma lógica própria, que é, sem dúvida, privatista — de lucratividade. Fica evidente aqui a 
incompatibilidade existente com o projeto ético-político hegemônico da profissão no Brasil, os princípios norteadores da categoria contidos no Código de Ética, onde a democracia, a autonomia dos indivíduos e a defesa dos direitos humanos compõem seu conjunto de diretrizes.

Assim, embora mantenha um discurso supraclassista e apolítico de "cidadania social" e preocupação desinteressada com as "desigualdades sociais", as ações das empresas "socialmente responsáveis" têm um caráter de classe, que objetiva tornar mais fácil seu processo de acumulação de capital e de controle social (dessa vez via consenso), sempre buscando a consolidação da hegemonia burguesa.

Para as empresas, ser socialmente responsável no discurso, na propaganda — ou até mesmo com ações isoladas, descontínuas e de baixo impacto - estimula o consumo de seus produtos ao mesmo tempo em que demonstra o lado "respeitável" e "humano" do capital — uma estratégia que pode ser modificada de acordo com a conveniência do mercado. As intenções do capital continuam as mesmas - lucro e acumulação, até como forma de sua sobrevivência mas agora revestidas por um sutil e eficaz verniz de respeitabilidade.

Artigo recebido em jan./2010 - Aprovado em jun./2010

\section{Referências bibliográficas}

AMARAL, M. V. B. Evidências de responsabilidade social no discurso do pacto global. In: XII CONGRESSO BRASILEIRO DE ASSISTENTES SOCIAIS. Rio de Janeiro: CFESS, 2007.

BEGHIN, N. A filantropia empresarial: nem caridade, nem direito. São Paulo: Cortez, 2005. (Questões da nossa época, v. 122.)

BEHRING, E. R. Brasil em contrarreforma: desestruturação do Estado e perda de direitos. São Paulo: Cortez, 2003.

; BOSCHETTI, I. Política social: fundamentos e história. São Paulo: Cortez, 2006a. (Biblioteca Básica do Serviço Social, v. 2.)

BOSCHETTI, I. et al. (Orgs.). Política social: alternativas ao neoliberalismo. Brasília: UnB, Programa de Pós-Graduação em Política Social, Departamento de Serviço Social, 2004. 
CÉSAR, M. J. Empresa-cidadã: uma estratégia de hegemonia. Tese (Doutorado em Serviço Social) — Universidade Federal do Rio de Janeiro, ESS. Rio de Janeiro: mimeo., 2005. $300 \mathrm{p}$.

FAES, I. A.; RUBIÃO, I. P. N. Projeto responsabilidade (sobre o) social. In: XI CONGRESSO BRASILEIRO DE ASSISTENTES SOCIAIS. Fortaleza: CFESS, 2004.

GARCIA, J. Considerações sobre a campanha pela responsabilidade social das empresas. In: XI CONGRESSO BRASILEIRO DE ASSISTENTES SOCIAIS. Fortaleza: CFESS, 2004.

O social como negócio das empresas. In: X CONGRESSO BRASILEIRO DE ASSISTENTES SOCIAIS. Rio de Janeiro: CFESS, 2001.

. Aspectos da questão social retraduzidos pela racionalidade empresarial. In: XII CONGRESSO BRASILEIRO DE ASSISTENTES SOCIAIS. Foz do Iguaçu: CFESS, 2007.

GÓIS, J. B. et al. Discursos do terceiro setor sobre o enfrentamento da questão social: o caso da "responsabilidade social empresarial". In: XI CONGRESSO BRASILEIRO DE ASSISTENTES SOCIAIS. Fortaleza: CFESS, 2004.

. Responsabilidade social empresarial e solidariedade: uma análise dos discursos dos seus atores. Serviço Social \& Sociedade, São Paulo, n. 78, p. 82-110, jul. 2004.

GROPPO, L. A. Responsabilidade social e a mercantilização da solidariedade. Serviço Social \& Sociedade, São Paulo, n. 91, p.143-62, set. 2007.

HARVARD BUSINESS REVIEW. Ética e responsabilidade social das empresas. São Paulo: Campus, 2005.

IAMAMOTO, M. V. As dimensões ético-políticas e teórico-metodológicas no Serviço Social contemporâneo. In: MOTA, Ana E. et al. (Orgs.). Serviço Social e Saúde. São Paulo: OPAS, OMS, Ministério da Saúde, Cortez, 2006. p. 161-196.

A questão social no capitalismo. Temporalis - Revista da Associação Brasileira de Ensino e Pesquisa em Serviço Social, Brasília, ano 2, n. 3, p. 9-32, jan./jul. 2001.

. O Serviço Social na contemporaneidade: trabalho e formação profissional. São Paulo: Cortez, 1998.

INSTITUTO ETHOS. Conceitos básicos e indicadores de responsabilidade social empresarial. 4. ed. Disponível em: <http://www.ethos.org.br>. Acesso em: 4 ago. 2007. 
KAMEYAMA, N. Ética empresarial. Revista Praia Vermelha, Rio de Janeiro, p. 148-66, 2004.

KARKOTLI, G. R. Responsabilidade social empresarial. Petrópolis: Vozes, 2006.

LEITE, I. C.; ALBERTASSE, L. As novas tendências no enfrentamento da questão social no Brasil. In: XII CONGRESSO BRASILEIRO DE ASSISTENTES SOCIAIS. Foz do Iguaçu: CFESS, 2007.

LIMA, G. L.; ANDRADE, E. T. Economia solidária em projetos de responsabilidade social empresarial: novo espaço de atuação para o assistente social. In: XII CONGRESSO BRASILEIRO DE ASSISTENTES SOCIAIS. Foz do Iguaçu: CFESS, 2007.

MARQUES, A. C. P. Uma análise sobre uma experiência de gestão social de um programa empresarial em comunidade de baixa renda. In: X CONGRESSO BRASILEIRO DE ASSISTENTES SOCIAIS. Rio de Janeiro: CFESS, 2001.

MARTINS, A. S. Estratégias burguesas de obtenção do consenso nos anos de neoliberalismo da Terceira Via. In: NEVES, Lúcia M. N. (Org.). A nova pedagogia da hegemonia: estratégias do capital para educar o consenso. São Paulo: Xamã, 2005.

MARX, K. O capital: crítica da economia política. 3. ed. São Paulo: Nova Cultural, 1988. v. I.

MENEZES, F. C. A relação entre o público e o privado no Brasil a partir dos anos 90: uma análise da chamada "Responsabilidade social das empresas" e de seus rebatimentos no Serviço Social sob o ponto de vista crítico. Dissertação (Mestrado) - Universidade do Estado do Rio de Janeiro, FSS. Rio de Janeiro, 2007. 141 p. (Mimeo.)

MESTRINER, M. L. O Estado entre a filantropia e a assistência social. 2. ed. São Paulo: Cortez, 2005.

MONTAÑO, C. Terceiro setor e questão social: crítica ao padrão emergente de intervenção social. 3. ed. São Paulo: Cortez, 2005.

. Das "lógicas do Estado" às "lógicas da sociedade civil": Estado e "terceiro setor" em questão. Serviço Social \& Sociedade, São Paulo, n. 59, p. 47-79, mar. 1999.

MOTA, A. E. Cultura da crise e seguridade social: um estudo sobre as tendências da previdência e da assistência social brasileira nos anos 80 e 90. 3. ed. São Paulo: Cortez, 2005.

(Org.). A nova fábrica de consensos: ensaios sobre a reestruturação empresarial, o trabalho e as demandas ao Serviço Social. 3. ed. São Paulo: Cortez, 2006. 
MOTA, A. E. et al. A nova cultura empresarial nos marcos do capitalismo contemporâneo. In: XII CONGRESSO BRASILEIRO DE ASSISTENTES SOCIAIS. Foz do Iguaçu: CFESS, 2007.

NETO, J. P. Capitalismo monopolista e Serviço Social. 4. ed. São Paulo: Cortez, 2005 .

NEVES, L. M. N.; SANT'ANNA, R. Introdução: Gramsci, o Estado educador e a nova pedagogia da hegemonia. In: NEVES, Lúcia M. N. (Org.). A nova pedagogia da hegemonia: estratégias do capital para educar o consenso. São Paulo: Xamã, 2005.

NOGUEIRA, M. Relações de trabalho e políticas sociais empresariais: análise dos efeitos da reestruturação produtiva das indústrias do setor eletroeletrônico da Zona Franca de Manaus a partir de 90. In: X CONGRESSO BRASILEIRO DE ASSISTENTES SOCIAIS. Rio de Janeiro: CFESS, 2001.

OLIVEIRA, C. Responsabilidade Social Empresarial e Empreendedorismo Social: tecendo algumas reflexões. In: XI Congresso Brasileiro de Assistentes Sociais. Fortaleza: CFESS, 2004.

OLIVEIRA, E. M. Responsabilidade social empresarial e o papel do assistente social: espaço alternativo de enfrentamento dos problemas sociais. In: X CONGRESSO BRASILEIRO DE ASSISTENTES SOCIAIS. Rio de Janeiro: CFESS, 2001.

PORTO, M. C. S. A assistência na crise da seguridade social brasileira: o "Terceiro Setor" e as políticas de combate à pobreza. In: X CONGRESSO BRASILEIRO DE ASSISTENTES SOCIAIS. Fortaleza: CFESS, 2004.

; SOARES, R. C. M. R. S. A assistência na crise da seguridade social brasileira: o "terceiro setor" e as políticas de combate à pobreza. In: X CONGRESSO BRASILEIRO DE ASSISTENTES SOCIAIS. Rio de Janeiro: CFESS, 2001.

PFEIFER, M. Balanço social: elementos de formação de consenso. In: XII CONGRESSO BRASILEIRO DE ASSISTENTES SOCIAIS. Foz do Iguaçu: CFESS, 2007.

RICO, E. M. O empresariado, a filantropia e a questão social. Serviço Social \& Sociedade, São Paulo, n. 58, p. 24-40, nov. 1998.

ROMAN, A. Responsabilidade social das empresas: um pouco de história e algumas reflexões. Revista FAE Business, n. 9, p. 36-38, set. 2004.

REVISTA Veja. Guia para se fazer o bem. Edição Especial. São Paulo: Abril, dez. 2001. $84 \mathrm{p}$.

SERRA, R. Estado, sociedade civil e responsabilidade social: o "terceiro setor" nesse contexto. In: XI CONGRESSO BRASILEIRO DE ASSISTENTES SOCIAIS. Fortaleza: CFESS, 2004. 
SCHMIDT, J.; SUGUIHIRO, V. L. Responsabilidade social empresarial: parceria interinstitucional trilhando caminhos para a sustentabilidade social. In: XII CONGRESSO BRASILEIRO DE ASSISTENTES SOCIAIS. Foz do Iguaçu: CFESS, 2007.

SPOSATI, A. O. A assistência social e a trivialização dos padrões de reprodução social. In: ___ _ FALCÃO, Maria do C.; TEIXEIRA, Sônia M. F. Os direitos (dos desassistidos) sociais. 3. ed. São Paulo: Cortez, 1995. p. 7-30.

TEIXEIRA, S. M. A (re)atualização das práticas filantrópicas no enfrentamento da questão social: um "novo" desenho de política social. In: XII CONGRESSO BRASILEIRO DE ASSISTENTES SOCIAIS. Foz do Iguaçu: CFESS, 2007.

TEMPORALIS - Revista da Associação Brasileira de Ensino e Pesquisa em Serviço Social, Brasília, ano 2, n. 3, jan./jul. 2001. 88 p.

TENÓRIO, F. G. (Org.). Responsabilidade social empresarial: teoria e prática. 2. ed. rev. e ampl. Rio de Janeiro: FGV, 2006. (Col. Fundação Getúlio Vargas Prática.)

TORRES, C. Responsabilidade social das empresas (RSE) e Balanço Social no Brasil. In: Ética e responsabilidade social. Disponível em: <www.balancosocial.org.br/media/ ART_2002_RSE_Vertical. pdf>. Acesso em: 26 jul. 2007.

VAZ, R. M. Empresa-cidadã, os programas sociais e seus impactos dentro e fora da empresa. In: X CONGRESSO BRASILEIRO DE ASSISTENTES SOCIAIS. Rio de Janeiro: CFESS, 2001.

VERONESE, M. A. F.; MUNIZ, P. P. Projeto Asas da Esperança: construindo a cidadania pela via da responsabilidade social. In: XI CONGRESSO BRASILEIRO DE ASSISTENTES Sociais. Fortaleza: CFESS, 2004.

YASBEK, M. C. Classes subalternas e assistência social. 4. ed. São Paulo: Cortez, 2003. 